\title{
Machine learning and soft computing applications in multimedia
}

Published online: 4 February 2021

(C) Springer Science+Business Media, LLC, part of Springer Nature 2021

Multimedia Tools and Applications gratefully acknowledges the editorial work of the scholars listed below on the special issue entitled "Machine Learning and Soft Computing Applications in Multimedia" (SI 1130 T).

Of 74 papers submitted to this issue, 12 were eventually accepted after a stringent peer review process.

\section{Corresponding Guest Editor}

\section{Srikanta Patnaik}

SOA University, Bhubaneswar, India

Email: patnaik_srikanta@yahoo.co.in

\section{Guest Editors}

\section{Heuiseok Lim}

Korea University, South Korea

Email: limhseok@korea.ac.kr

\section{Hakim Bendjenna}

University of Larbi Tebessi, Algeria

Email: hbendjenna@gmail.com

\section{Jae Moon Lee}

Hansung University, Seoul, South Korea

Email: jmlee@hansung.ac.kr

Publisher's note Springer Nature remains neutral with regard to jurisdictional claims in published maps and institutional affiliations. 